\title{
The time course of mandelic and phenylglyoxylic acid excretion in workers exposed to styrene under model conditions
}

\author{
H. K. WILSON, J. COCKER, C. J. PURNELL, R. H. BROWN, AND \\ D. GOMPERTZ \\ From the Health \& Safety Executive, Occupational Medicine and Hygiene Laboratory, \\ 403 Edgware Road, London NW2 $6 L N$
}

ABSTRACT Urinary excretion of mandelic and phenylglyoxylic acids by two technicians building glass-reinforced plastic boats has been measured over a 7-day period. Peak excretion of both metabolites occurred several hours after the end of exposure. There was little relationship between urinary mandelic acid concentrations measured at the end of shift and the maximum excretion observed in samples collected after this time. It is suggested that sampling strategies devised to monitor workers exposed to styrene should reflect maximum excretion rates of urinary mandelic acid.

The metabolism of styrene has been extensively studied in both man and animals (Bardodej and Bardodejova, 1970; Leibman and Ortiz, 1970; Leibman, 1975; Ryan and Bend, 1977). The major products of styrene metabolism in man are mandelic and phenylglyoxylic acids (Ohtsuji and Ikeda, 1970; Caperos and Fernandez, 1976; Guillemin and Bauer, 1976; Van Roosmalen and Drummond, 1978). Numerous studies have been reported establishing a correlation between occupational styrene exposure and the excretion of mandelic acid in urine (Slob, 1973; Buchet et al., 1974; Härkönen et al., 1974; Ikeda et al., 1974; Norseth, 1974; Engstrom et al., 1976; Evans et al., 1977). In the design of these studies little attention has been paid to the kinetics of mandelic acid production and excretion. Although Engstrom et al. (1976) reported the variability in the half-life of mandelic acid elimination, such pharmacokinetic data have not been used to establish a strategy for biological monitoring of workers exposed to styrene.

In this study we have continuously monitored the mandelic and phenylglyoxylic acid excretion of two technicians involved in an exercise designed to establish optimum ventilation conditions during the manufacture of glass-reinforced plastic boats. This study was also designed to give detailed exposure information and to allow correlation between various forms of static and personal monitoring devices: these data are presented elsewhere.

Received for publication 4 December 1978 Accepted for publication 10 January 1979
The results of the measurements of urinary mandelic and phenylglyoxylic acid excretion are discussed in relation to an optimum strategy for biological monitoring.

\section{Methods}

\section{EXPERIMENTAL DESIGN}

The two workers monitored over the 7 days of the experiment were involved in a ventilation and environmental monitoring exercise. During this exercise, moulds for a 5-metre boat hull and its superstructure were used under controlled conditions to make a 3-ply glass-reinforced plastic hull and a 2-ply deck moulding during each alternate shift. The hull and deck moulds received a gel-coat by brushing, followed by the required ply of resin/glass fibre mat by hand lay-up (laminating). A general purpose polyester resin dissolved in styrene was used. Ventilation conditions were modified from shift to shift; there were two shifts per day.

Both operatives were provided with accommodation near the exercise and agreed to collect all urine samples over the 7-day period. The urine samples were frozen and stored at $-30^{\circ} \mathrm{C}$ as soon after voiding as possible, and were not thawed until analysis.

\section{ANALYSIS OF URINARY METABOLITES}

Mandelic and phenylglyoxylic acids were analysed by gas chromatography as their trimethylsilyl derivatives.

Following the addition of phenyllactic acid 
$(5 \mu \mathrm{mol})$ as internal standard, urine samples $(1 \mathrm{ml})$ were adjusted to $\mathrm{pH} 1$ with $2 \mathrm{M}$ hydrochloric acid and extracted with diethyl ether $(10 \mathrm{ml})$. The solvent was evaporated and the residue silylated with BSTFA (N,O-bis-(trimethylsilyl)-trifluoroacetamide) $(200 \mu \mathrm{l})$ and pyridine $(100 \mu \mathrm{l})$ for $5 \mathrm{~min}$ at room temperature. The resulting solution was analysed by gas chromatography. A linear calibration graph was obtained using standard solutions of mandelic acid (up to $20 \mathrm{mmol} / \mathrm{l}$ ) and phenylglyoxylic acid (up to $10 \mathrm{mmol} / \mathrm{l}$ ) by expressing the peak area ratio of sample to internal standard against concentration. Quality control samples were analysed with every tenth sample.

For chromatography, a Perkin Elmer F17 gas chromatograph fitted with a flame ionisation detector was used. The glass column (internal diameter, $3 \mathrm{~mm}$; height $2 \mathrm{~m}$ ) was packed with $3 \%$ OV17 on Chromosorb W (80-100 mesh). The injector and detector temperature was set at $175^{\circ} \mathrm{C}$ and the column temperature at $140^{\circ} \mathrm{C}$. The flow rate of nitrogen through the column was $40 \mathrm{ml} / \mathrm{min}$.

The concentration of both metabolites are expressed in terms of creatinine excretion. Urinary creatinine was measured by the Jaffe method using a Technicon AA2 Autoanalyser system.

The exposure of the two technicians to styrene was monitored using personal sampling pumps and charcoal absorption tubes (Simmons and Moss, 1973). The styrene was desorbed from the charcoal with carbon disulphide and estimated by gas chromatography on a Carbowax $20 \mathrm{M}$ column $(2 \mathrm{~m} \times 3 \mathrm{~mm}$ i.d.) using a flame ionisation detector.

\section{Results}

The time-weighted average exposure for both operatives varied from $254 \mathrm{ppm}$ during the first shift (no ventilation) to a minimum of $34 \mathrm{ppm}$ during one of the ventilation exercises. These exposures and the concentrations of mandelic and phenylglyoxylic acids in the urine specimens from each worker are presented in the Figure.

It can be seen that the peak excretion for both metabolites in terms of creatinine concentration occurs several hours after the end of the shift in which exposure took place. There is a parallel between the excretion of mandelic and phenylglyoxylic acids, so that although the ratio between these varies from one urine specimen to another, the overall time course is the same. The time of maximum excretion of both metabolites appears constant for each worker, operative A showing a maximum excretion rate 8 hours after the end of shift on at least the first 3 days, and operative B showing maximum excretion 4 hours after work on four occasions. The

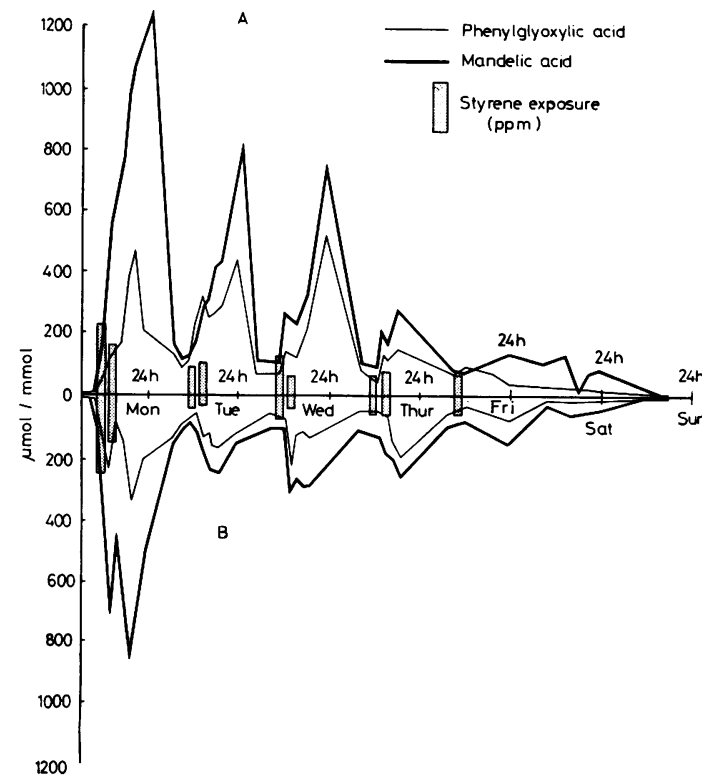

Figure Urinary excretion of mandelic and phenylglyoxylic acids and its relationship to styrene exposure. The urinary concentration of the twa metabolites for technician $A$ are plotted upwards from the horizontal axis and those from technician $B$, downwards. The values on the ordinate refer both to metabolite excretion ( $\mu \mathrm{mol}$ of mandelic acid or phenylglyoxylic acid/mmol of creatinine) and to styrene exposure (time-weighted average; parts per million).

data also show that there is minimal relationship between peak excretion and the concentration of mandelic acid in urine samples taken early the following morning or directly at the beginning of the next shift.

\section{Discussion}

This detailed study of two individuals exposed to styrene under well-documented working conditions enables some conclusions to be drawn about the optimum strategy for collecting urine samples for biological monitoring.

Previousstudies have reported correlations between mandelic acid concentration in end-of-shift urine samples and styrene exposure. The correlations reported in these earlier studies have been poor with inter-worker variability surprisingly high. The data from Engstrom et al. (1976) show how wide the range of excretion rates is for urinary mandelic acid, the half-life varying from 4.7 to 11.9 hours. It can be seen from these data that the peak excretion of mandelic acid will occur at a wide range of times 
after exposure has ended. The data from the two workers presented here show that peak excretion occurs 4 and 8 hours after the end of the exposure. Any sampling procedure dependent on a single urine specimen would not allow for this variability in peak excretion time. One possible method is to collect and pool all urine specimens passed from the end of one shift until the beginning of the next shift. However, work practices vary so that, for certain members of the work force, significant exposure occurs only during the first few hours of the working day. Under these conditions peak excretion may occur before the end of the working period. One approach for dealing with varying exposures during the day would be to collect urine from beginning of work until the end of the waking day. Such a procedure would ensure that the peak excretion period is monitored irrespective of different metabolism and clearance rates and work practices within the working population.

If such a sampling strategy were accepted, the values for mandelic acid excretion for a specific styrene exposure would have to be revised. A preliminary but limited survey using this sampling programme has demonstrated to us that it is acceptable to the work force, and that a better correlation between styrene exposure and mandelic acid excretion is obtainable.

The data presented here for phenylglyoxylic acid excretion show the same time course as mandelic acid excretion, but the ratio between the two metabolites varies considerably from day to day. The sum of the excretion of the two metabolites has been used previously (Ohtsuji and Ikeda, 1970), and the results from our study appear to support such an approach. However, unless urine samples are frozen immediately after collection there is a steady loss of phenylglyoxylic acid due to spontaneous decarboxylation. A further problem is the difficulty in producing a single derivative of phenylglyoxylic acid that is suitable for gas chromatography. Further studies are therefore required to establish whether the measurement of phenylglyoxylic acid, either independently or after reduction to mandelic acid (Guillemin and Bauer, 1976) to give a total excretion for the two metabolites, is a useful procedure.

We thank Mr P. Jones and Mr P. Evans of BP Chemicals Ltd (Resin Branch), Barry, for their cooperation and help with the design and execution of this study.

\section{References}

Bardodej, Z., and Bardodejova, E. (1970). Biotransformation of ethylbenzene, styrene and a-methyl styrene in man. American Industrial Hygiene Association Journal, 31, 206209.

Buchet, J. P., Lauwerys, R., and Roels, H. (1974). Évaluation de l'exposition des travailleurs au styrène par le dosage de ses métabolites urinaires: les acides mandélique et phenylglyoxylique. Archives des Maladies Professionnelles de Médecine du Travail et de Sécurité Sociale, 35, 511-516.

Caperos, J. R., and Fernandez, J. G. (1976). Determination of urinary mandelic acid and phenylglyoxylic acid by gas chromatography. Archives des Maladies Professionnelles de Médecine du Travail et de Sécurité Sociale, 37, 387-391.

Engstrom, K., Härkönen, H., Kalliokoski, P., and Rantanen, J. (1976). Urinary mandelic acid concentration after occupational exposure to styrene and its use as a biological exposure test. Scandinavian Journal of Work, Environment and Health, 2, 21-26.

Evans, M., Molyneux, M., Sharp, T., Bailey, A., and Hollingdale-Smith, P. (1977). The practical application of the Porton diffusion sampler for the measurement of timeweighted average exposure to volatile organic substances in air. Annals of Occupational Hygiene, 20, 357-363.

Guillemin, M., and Bauer, D. (1976). Human exposure to styrene. International Archives of Occupational and Environmental Health, 37, 57-64.

Härkönen, H., Kalliokoski, P., Hietala, S., and Hernberg, S. (1974). Concentration of mandelic and phenylglyoxylic acid in urine as indicators of styrene exposure. Work, Environment and Health, 11, 162-169.

Ikeda, M., Imamura, T., Hayashi, M., and Tabuchi, T. (1974). Evaluation of hippuric acid, phenylglyoxylic acid and mandelic acid in urine as indices of styrene exposure. Internationales Archiv für Arbeitsmedizin, 32, 93-101.

Leibman, K. C. (1975). Metabolism and toxicity of styrene. Environmental Health Perspectives, 11, 115-119.

Leibman, K. C., and Ortiz, E. (1970). Epoxide intermediates in microsomal oxidation of olefins to glycols. Journal of Pharmacology and Experimental Therapeutics, 173, 242-246.

Norseth, T. (1974). Styreneksposisjon ved produksjon av plastbater. Tiddskrift for Kjemi, Bergvesen og metallurgi, 34, 11-13.

Ohtsuji, H., and Ikeda, M. (1970). A rapid colorimetric method for the determination of phenylglyoxylic acid and mandelic acids. British Journal of Industrial Medicine, 27, $150-154$.

Ryan, A. J., and Bend, J. R. (1977). The metabolism of styrene oxide in the isolated perfused rat liver. Drug Metabolism and Disposition, 5, 363-367.

Simmons, J. H., and Moss, I. M. (1973). Measurement of personal exposure to 1,1,1-trichloroethane and trichloroethylene using an inexpensive sampling device and batteryoperated pump. Annals of Occupational Hygiene, 16, 47-49.

Slob, A. (1973). A new method for determination of mandelic acid excretion at low level styrene exposure. British Journal of Industrial Medicine, 30, 390-393.

Van Roosmalen, P. B., and Drummond, I. (1978). Simultaneous determination by gas chromatography of the major metabolites in urine of toluene, xylenes and styrene. British Journal of Industrial Medicine, 35, 56-60. 